\title{
Prevalence of persistent pain after breast cancer treatment by detection mode among participants in population-based screening programs
}

Anabel Romero ${ }^{1 *}$ (D), Isabel Torà-Rocamora', Marisa Baré2, Teresa Barata ${ }^{3}$, Laia Domingo ${ }^{1,5}$, Joana Ferrer ${ }^{4}$, Núria Torà ${ }^{2}$, Mercè Comas ${ }^{1}$, Carmen Merenciano ${ }^{3}$, Francesc Macià', Xavier Castells', Maria Sala ${ }^{1}$ and CAMISS Study Group

\begin{abstract}
Background: To date, the study of the risks and benefits of breast cancer screening has not included the onset of persistent pain after breast cancer treatment within the context of population-based screening programs. Our purpose was to investigate the prevalence of persistent pain and associated factors in women diagnosed with breast cancer (screening or interval) in the context of a population-based breast cancer screening program in Spain.

Methods: A total of 1,057 women participating in a population-based breast cancer screening program were diagnosed with breast cancer between 2000 and 2008. The women were treated surgically and followed-up to 2013. The risk of developing persistent pain was estimated through multivariate logistic regression analysis.

Results: Breast cancer was detected during routine screening in 732 women (69.3\%) and emerged as an interval cancer between two screening rounds in 325 (30.7\%). Persistent pain was present in 118 women (11.3\%). Women diagnosed through routine screening reported a higher prevalence of persistent pain (12.9\%) than those with interval cancers $(7.8 \%)(P<0.05)$. Multivariate logistic regression analysis identified two other variables associated with persistent pain: having a Charlson index $>=2$ (Odds Ratio [OR]: $4.595 \%$ Confidence Interval [Cl]: 2.1-9.5) versus no comorbidities, and having undergone an axillary lymph node dissection (OR: $2.095 \%$ Cl: 1.0-4.0) versus sentinel lymph node biopsy.
\end{abstract}

Conclusions: The prevalence of persistent pain was relatively low. The detection mode was not related to the onset of persistent pain. The factors associated with persistent pain were a Charlson index $>=2$ and the performance of axillary lymph node dissection. Women treated for breast cancer are at risk for developing persistent pain regardless of the detection mode, especially those with comorbidities and those who have undergone axillary lymph node dissection.

Keywords: Breast cancer, Complications, Persistent pain, Screening, Comorbidities, Interval cancer

\footnotetext{
* Correspondence: aromero@imim.es

'Department of Epidemiology and Evaluation, IMIM-Hospital del Mar,

Research Network on Health Services in Chronic Diseases (REDISSEC), Passeig

Marítim 25-29, Barcelona 08003, Spain

Full list of author information is available at the end of the article
} 


\section{Background}

Breast cancer is the most frequent malignancy among Spanish women, with an estimated 25,215 new cases in 2012 [1]. Screening programs and improved treatments have reduced mortality from this disease [2]. Early detection allows more effective treatment, but the treatment itself is not free of complications in the short term or sequels in the long term. Women with interval cancer (cancers detected clinically after a negative screening round and before the following screening invitation) may not benefit from early detection because of a delay in diagnosis and less favourable biological tumor characteristics [3].

To date, complications have not been evaluated by according to the detection method. Among complications, persistent pain, defined by some authors as pain in the breast area, axilla, shoulder or arm for more than 3 months after breast cancer surgery, has been reported as one of the most frequent long-term complications [4]. Among patients treated surgically for breast cancer, the prevalence of persistent pain may range from $10 \%$ to $50 \%$ or more, depending on the characteristics of the population studied, as well as on the definition of persistent pain [4-16]. Several factors have been associated with the risk of developing persistent pain: young age $[5-7,10,12,14,16,17]$ adjuvant therapies (chemotherapy or radiotherapy) $[5,11]$, axillary lymph node dissection (ALND) [5-7, 10, 12], and the presence of comorbidities $[5,16]$, among others, but the evidence remains inconclusive.

Given that a substantial number of women are diagnosed with breast cancer and that most are treated surgically, a large number of women can be expected to experience persistent pain, which may negatively affect their quality of life and psychosocial well-being. Therefore, from the perspective of public health, persistent pain in women treated for breast cancer is an important health problem. To date, study of the risks and benefits of breast cancer screening has not included the onset of complications and sequels after breast cancer treatment within the context of population-based screening programs. Women with screen-detected breast cancer benefit from early detection and have better survival $[18,19]$. However, no studies have evaluated whether these women also benefit from fewer complications and have less persistent pain in the long term. The risk-benefit analysis of breast cancer screening should include information on complications in women with screen-detected breast cancer.

We aimed to investigate the prevalence of persistent pain and associated factors in women diagnosed with breast cancer (screening or interval) in the context of a population-based breast cancer screening program in Spain.

\section{Methods}

\section{Study population}

Our study population was drawn from the CAMISS cohort, which includes 1,086 women with breast cancer from a population-based screening program. These women were diagnosed with breast cancer between 2000 and 2008 and were followed-up to December 2013. Breast cancer was detected in routine screening or emerged as an interval cancer. The definition of interval cancer used was that proposed in the European guidelines as "primary breast cancer arising after a negative screening episode, with or without further assessment, and before the next screening invitation, or within 24 months for women who reached the upper age limit" [20].

All women were resident in Spain, were aged 50 to 69 years at diagnosis, and were from 2 Spanish regions: the Canary Islands and Catalonia. In Spain, all women aged 50 to 69 years are actively invited to participate in the population-based screening program by a written letter every 2 years, following the European guidelines for Quality Assurance in Mammographic Screening Recommendations. This nationwide program achieves the required standards [21].

\section{Study variables}

Interval cancers were identified by merging data from the registers of screening programs with populationbased cancer registries, the regional Minimum Data Set and hospital-based cancer registries. Further details on the identification of interval cancers are reported elsewhere [3]. For the purpose of this study, only two categories were considered in the final analysis: interval or screening cancers.

Women's age at diagnosis was obtained from the date of birth and date of the screening mammogram. The presence of other comorbidities was identified at clinical records review. All the comorbidities recorded in the clinical records at the date of breast cancer diagnosis were considered, although we only included the comorbidities needed to calculate the Charlson index [22]. Tumor-related characteristics (histological type and grade, focality, size, lymph node involvement, estrogen receptor $[E R]$, progesterone receptor $[\mathrm{PR}]$, human epidermal growth factor receptor 2 [HER2] status) were obtained from the cancer registries, hospital-based registers, and from clinical records. Based on expression of ER, PR and HER2, tumors were classified into four phenotypes: 1) luminal A: ER+/HER2- OR PR+/HER2-; 2) luminal B: ER+/HER2+ or PR+/HER2+; 3) HER2: ER-/PR-/HER2+; and 4) triple-negative: ER-,PR-, HER2- [23].

Information on the treatments received was obtained from the clinical records. Two types of surgery were considered: radical or conservative. Women with radical surgery included all those who underwent mastectomies, 
whether radical or simple. In both cases, the breast is completely removed. In conservative surgery, only the tumor and some of the healthy surrounding tissue are excised, and the breast is fully preserved.

In addition to breast surgery, some women could undergo an ALND, also a surgical procedure that incises the axilla to identify, examine and remove lymph nodes. Sentinel lymph node biopsy (SLNB) has been proposed as an alternative to ALND, because it produces less morbidity [24]. SLNB was a relatively new technique during the study period and was introduced at different times in each hospital. It was introduced in the first hospital in 2000 and in the last hospital in 2004.

Chemotherapy, radiotherapy, hormone therapy or specific Her2 treatment may have been used as an adjuvant therapy before and/or after surgery.

\section{Outcome variables}

The onset of breast cancer treatment complications was reviewed throughout the patient's clinical course, starting from the date of surgery until the end of follow up. The reviewers recorded the onset of the following complications: persistent pain, lymphedema, anxiety, fatigue, disability, osteoporosis, agranulocytosis, lymphopenia, seroma, weight gain, paraesthesia, infection, necrosis, cardiomyopathy, cognitive dysfunction, pneumonitis, mycosis, hypothyroidism, renal toxicity, ototoxicity, pulmonary fibrosis and other complications not specified.

The definition of persistent pain was the following: a woman was considered to have persistent pain if she felt pain in the area of the operated breast, axilla, shoulder or arm in some of the follow-up visits at least 3 months after surgery [25]. The pain could be neuropathic or not. According to this definition, in the clinical record review, a woman was considered to have pain if, in some of the follow-up visits (at least one visit 3 months after surgery), the physician assessing her reported the presence of pain in some of the previously described areas (operated breast area, axilla, shoulder or arm). The clinical record review was performed by trained staff (nurses) at each of the participating centers.

\section{Statistical analysis}

We performed a descriptive analysis of the study variables. The prevalence of overall complications were estimated, as well as the prevalence of persistent pain and its $95 \%$ confidence intervals (CI). The prevalence of overall complications was computed as the number of women with at least one complication among the total number of women with information on the complications variable.

Comparisons were made between women with screening-detected cancers and those with interval cancers. Statistical significance was estimated using the chi-square or Fisher exact tests, since all the study variables were considered as categorical. The prevalence of persistent pain were described by detection mode, age at diagnosis, Charlson index, tumor characteristics and breast cancer treatments. The crude and adjusted risk of developing persistent pain was estimated through a multivariate logistic regression analysis. The multivariate logistic regression model included the following variables: detection method, age, Charlson index, histological type, phenotype, axillary treatment, neoadjuvant treatment and chemotherapy after surgery. Statistical significance was considered if the $P$-value was $<0.05$. Statistical analyses were performed using the SPSS statistical package (version 12.0).

\section{Results}

Of the 1,086 women included in the CAMISS cohort, most were treated surgically $(n=1,057,97.3 \%)$ and were included in the analysis. Breast cancer was detected during routine screening mammograms in 732 women (69.3\%) and emerged as interval cancer in 325 (30.7\%). The characteristics of the women and detected tumors by detection mode, as well as the treatments provided, are shown in Table 1. Women with interval cancers had larger tumors, with a higher percentage of positive lymph node involvement (44.4\% vs. $25.8 \%$; $P<0.001)$. The percentage of ductal in situ tumors was higher among women with screen-detected tumors $(11.1 \%$ vs. $3.8 \% ; P<0.001)$. Histological grade III was more frequent among women with interval cancers (42.3\% vs. $24.2 \% ; P<0.001)$, as well as among those with triple negative phenotype $(16.1 \%$ vs. $8.1 \%$; $P<0.001)$. Women with interval cancer were younger than those with screendetected cancers $(P<0.001)$. No differences in the Charlson index were observed according to the detection method. Most women underwent conservative surgery $(n=829$, $78.6 \%)$. According to the detection method, radical surgery was more common among women with interval cancers $(33.0 \%)$ than in those with screen-detected cancers $(16.3 \%)(P<0.001)$. ALND was more common in women with interval cancers than in those with screen-detected tumors $(78.4 \%$ vs. $70.6 \% P<0.05)$. Neoadjuvant therapy was more frequent in women in the interval cancer group than in the screening group ( $24.0 \%$ vs. $4.2 \% P<0.001)$.

A total of 313 women (29.6\% $95 \%$ CI: 27.4 -33.0) experienced at least one complication during follow-up. Among all the complications reported, the most frequent was persistent pain, which was present in 118 women (11.3\% 95 \% CI: 9.4-13.2). Women who were diagnosed in routine screening reported a higher prevalence of persistent pain $(12.9 \% 95 \% \mathrm{CI}: 10.4$-15.3) than those with tumors that emerged as interval cancers between two screening rounds $(7.8 \% 95 \% \mathrm{CI}: 4.8-10.7)(P<0.05)$ (Table 1$)$.

Table 2 shows the prevalence of persistent pain according to women's characteristics, the detection method and tumor characteristics. Women aged 65-70 
Table 1 Tumor and women's characteristics, treatments performed and frequencies of complications, according to detection method

\begin{tabular}{|c|c|c|c|c|c|c|c|}
\hline & \multicolumn{2}{|c|}{ Screen-detected cancers } & \multicolumn{2}{|c|}{ Interval cancers } & \multirow[t]{2}{*}{$P$-value } & \multicolumn{2}{|l|}{ Total } \\
\hline & $\mathrm{N}$ & $\%$ & $\mathrm{~N}$ & $\%$ & & $\mathrm{~N}$ & $\%$ \\
\hline Total women & 732 & 69.3 & 325 & 30.7 & & 1057 & 100.0 \\
\hline Tumor size $(n=936)$ & & & & & $<0.001$ & & \\
\hline$<=10 \mathrm{~mm}$ & 198 & 31.9 & 40 & 12.7 & & 238 & 25.4 \\
\hline 11 to $20 \mathrm{~mm}$ & 273 & 44.0 & 117 & 37.0 & & 390 & 41.7 \\
\hline 21 to $50 \mathrm{~mm}$ & 132 & 21.3 & 133 & 42.1 & & 265 & 28.3 \\
\hline$>50 \mathrm{~mm}$ & 17 & 2.7 & 26 & 8.2 & & 43 & 4.6 \\
\hline Lymph node involvement $(n=1054)$ & & & & & $<0.001$ & & \\
\hline Negative & 542 & 74.2 & 180 & 55.6 & & 722 & 68.5 \\
\hline Positive & 188 & 25.8 & 144 & 44.4 & & 332 & 31.5 \\
\hline Number of positive nodes $(n=870)$ & & & & & $<0.05$ & & \\
\hline$=<3$ & 515 & 92.5 & 268 & 85.6 & & 783 & 90.0 \\
\hline $4-20$ & 38 & 6.8 & 41 & 13.1 & & 79 & 9.1 \\
\hline$>20$ & 4 & 0.7 & 4 & 1.3 & & 8 & 0.9 \\
\hline Histological type $(n=1050)$ & & & & & $<0.001$ & & \\
\hline Ductal Infiltrante & 531 & 72.7 & 242 & 75.6 & & 773 & 73.6 \\
\hline Ductal In situ & 81 & 11.1 & 12 & 3.8 & & 93 & 8.9 \\
\hline Lobular & 63 & 8.6 & 36 & 11.3 & & 99 & 9.4 \\
\hline Otros & 55 & 7.5 & 30 & 9.4 & & 85 & 8.1 \\
\hline Focality $(n=894)$ & & & & & 0.643 & & \\
\hline Unifocal & 487 & 83.5 & 256 & 82.3 & & 743 & 83.1 \\
\hline Multifocal and/or multicentric & 96 & 16.5 & 55 & 17.7 & & 151 & 16.9 \\
\hline Histological grade $(n=914)$ & & & & & $<0.001$ & & \\
\hline । & 181 & 28.8 & 48 & 16.8 & & 229 & 25.1 \\
\hline$\|$ & 249 & 39.6 & 104 & 36.4 & & 353 & 38.6 \\
\hline III & 152 & 24.2 & 121 & 42.3 & & 273 & 29.9 \\
\hline Not applicable & 46 & 7.3 & 13 & 4.5 & & 59 & 6.5 \\
\hline Tumor phenotype $(n=769)$ & & & & & $<0.001$ & & \\
\hline Luminal A & 275 & 56.9 & 132 & 46.2 & & 407 & 52.9 \\
\hline Luminal B & 131 & 27.1 & 79 & 27.6 & & 210 & 27.3 \\
\hline HER2 & 38 & 7.9 & 29 & 10.1 & & 67 & 8.7 \\
\hline Triple negative & 39 & 8.1 & 46 & 16.1 & & 85 & 11.1 \\
\hline Age $(n=1057)$ & & & & & $<0.001$ & & \\
\hline $50-54$ & 193 & 26.4 & 117 & 36.0 & & 310 & 29.3 \\
\hline $55-59$ & 183 & 25.0 & 100 & 30.8 & & 283 & 26.8 \\
\hline $60-64$ & 211 & 28.8 & 67 & 20.6 & & 278 & 26.3 \\
\hline $65-70$ & 145 & 19.8 & 41 & 12.6 & & 186 & 17.6 \\
\hline Charlson index $(n=1057)$ & & & & & 0.380 & & \\
\hline 0 & 535 & 73.1 & 241 & 74.2 & & 776 & 73.4 \\
\hline 1 & 129 & 17.6 & 53 & 16.3 & & 182 & 17.2 \\
\hline$>=2$ & 68 & 9.3 & 31 & 9.5 & & 99 & 9.4 \\
\hline Surgery $(n=1055)$ & & & & & $<0.001$ & & \\
\hline Radical & 119 & 16.3 & 107 & 33.0 & & 226 & 21.4 \\
\hline Conservative & 612 & 83.7 & 217 & 67.0 & & 829 & 78.6 \\
\hline
\end{tabular}


Table 1 Tumor and women's characteristics, treatments performed and frequencies of complications, according to detection method (Continued)

\begin{tabular}{|c|c|c|c|c|c|c|c|}
\hline \multicolumn{3}{|c|}{ Axillary treatment: SLNB and $\operatorname{ALND}^{c}(n=994)$} & \multicolumn{5}{|c|}{$<0.05$} \\
\hline Only SLNB & 201 & 29.4 & 67 & 21.7 & & 268 & 27.0 \\
\hline ALND & 483 & 70.6 & 243 & 78.4 & & 726 & 73.0 \\
\hline Neoadjuvant therapy $(n=1057)$ & & & & & $<0.001$ & & \\
\hline No & 701 & 95.8 & 247 & 76.0 & & 948 & 89.7 \\
\hline Yes & 31 & 4.2 & 78 & 24.0 & & 109 & 10.3 \\
\hline Adjuvant therapy $(n=1051)$ & & & & & 0.387 & & \\
\hline No & 16 & 2.2 & 10 & 3.1 & & 26 & 2.5 \\
\hline Yes & 712 & 97.8 & 313 & 96.9 & & 1025 & 97.5 \\
\hline Any complication ${ }^{\mathrm{a}}(n=1057)$ & 225 & 30.7 & 88 & 27.1 & 0.229 & 313 & 29.6 \\
\hline Persistent pain ${ }^{\mathrm{b}}(n=1045)$ & 93 & 12.9 & 25 & 7.8 & $<0.05$ & 118 & 11.3 \\
\hline
\end{tabular}

${ }^{\mathrm{a}}$ Number of women with at least one complication

${ }^{b}$ Number of women with persistent pain

'SLNB: sentinel lymph node biopsy. In this category only women with SLNB performed were included. ALND: axillary lymph node dissection. This category includes women with only ALND performed and women with SLNB and ALND

years had a lower prevalence of persistent pain $(8.7 \%)$ than those from other age groups (50-54 years: $11.8 \%$, 55-59 years: $13.2 \%$, 60-64 years: $10.5 \%)$. However, these differences were not statistically significant $(P=$ $0.483)$. A gradient was observed in the prevalence of persistent pain, according to the Charlson index. Women without other comorbidities (Charlson index $=0$ ) had the lowest prevalence of persistent pain (8.5\%), whereas those with a Charlson index $>=2$ had the highest prevalence of persistent pain $(21.9 \%)(P<0.001)$. According to the detection method, women with screen-detected tumors had a higher prevalence of persistent pain than women with interval tumors $(12.9 \%$ vs. $7.8 \% P<0.05)$. When tumor characteristics were analyzed, the prevalence of persistent pain was higher among women with lobular histological type tumors $(14.3 \%)(P<0.05)$. No statistically significant differences in the prevalence of persistent pain were observed by tumor size, lymph node involvement, focality, histology or phenotype.

Table 3 shows the prevalence of persistent pain according to the treatments provided. The prevalence of persistent pain was higher among women who underwent ALND than in those who underwent SLNB only (13.7 \% vs. $6.7 \% P<0.001)$. The prevalence was also higher in women who received chemotherapy after surgery than those who did not $(14.5 \%$ vs. $8.4 \% P<0.01)$. No statistically significant differences in persistent pain prevalence were observed according to the type of surgery, neoadjuvant therapy, radiotherapy, hormone therapy or Her2 treatment after surgery.

The factors associated with persistent pain were described using univariate and multivariate logistic regression models (Table 4). In the univariate analysis, five factors were associated with persistent pain (detection method, Charlson index, histological type, axillary treatment and chemotherapy after surgery). In the multivariate model, only the Charlson index remained statistically significant, with the highest odds ratio (OR). Women with a Charlson index $>=2$ had an OR of 4.5 (95\% CI: 2.1 -9.5) with respect to women without comorbidities (Charlson index $=0$ ). Persistent pain was also more frequent among patients with ALND than in those with SLNB only, although this result was at the limit of statistical significance (OR: 2.095 \% CI: 1.0 - 4.0).

\section{Discussion}

The prevalence of persistent pain was higher in women diagnosed within the screening program than in those with interval cancers. Our first hypothesis was that, given the benefits of screening (early diagnosis, with less aggressive tumors), the treatment of screen-detected cancer would be less intensive and, therefore, have fewer complications. Surprisingly, we observed that women diagnosed within the screening program did not benefit from fewer complications; on the contrary, they initially seemed to have more persistent pain. However, in the multivariate analysis only two factors showed a clear association with the onset of persistent pain: the presence of other comorbidities and the performance of an ALND.

The prevalence of persistent pain in our study was $11.3 \%$. This prevalence is relatively low compared with that in other studies, which include all diagnostic methods and women of different ages, with values ranging from $10 \%$ to $50 \%$ or more $[4,5,7-12,14,16]$. In our study, information on the presence of persistent pain was extracted through the medical records review. Women were considered to have persistent pain if they 
Table 2 Prevalence of persistent pain according to detection method, tumor and women's characteristics

\begin{tabular}{|c|c|c|}
\hline & \multicolumn{2}{|c|}{ Persistent pain ${ }^{a}$} \\
\hline & N (\%) & $P$-value \\
\hline \multicolumn{3}{|l|}{ Women's characteristics } \\
\hline Age $(n=1045)$ & & 0.483 \\
\hline $50-54(n=305)$ & $36(11.8)$ & \\
\hline $55-59(n=281)$ & $37(13.2)$ & \\
\hline $60-64(n=275)$ & $29(10.5)$ & \\
\hline $65-70(n=184)$ & $16(8.7)$ & \\
\hline Charlson index $(n=1045)$ & & $<0.001$ \\
\hline $0(n=769)$ & $65(8.5)$ & \\
\hline $1(n=180)$ & $32(17.8)$ & \\
\hline$>=2(n=96)$ & $21(21.9)$ & \\
\hline \multicolumn{3}{|l|}{ Detection method $(n=1045)$} \\
\hline Screen-detected tumors $(n=723)$ & $93(12.9)$ & $<0.05$ \\
\hline Interval tumors $(n=322)$ & $25(7.8)$ & \\
\hline \multicolumn{3}{|l|}{ Tumor characteristics } \\
\hline Tumor size $(n=932)$ & & 0.907 \\
\hline$<=10 \mathrm{~mm}(n=237)$ & $14(5.9)$ & \\
\hline 11 to $20 \mathrm{~mm}(n=387)$ & $28(7.2)$ & \\
\hline 21 to $50 \mathrm{~mm}(n=265)$ & $19(7.2)$ & \\
\hline$>50 \mathrm{~mm}(n=43)$ & $2(4.7)$ & \\
\hline Lymph node involvement ( $n=1042)$ & & 0.564 \\
\hline Negative $(n=713)$ & $78(10.9)$ & \\
\hline Positive $(n=329)$ & $40(12.2)$ & \\
\hline Number of positive nodes $(n=866)$ & & 0.442 \\
\hline$=<3(n=781)$ & $54(6.9)$ & \\
\hline $4-20(n=77)$ & $7(9.1)$ & \\
\hline$>20(n=8)$ & $1(12.5)$ & \\
\hline Histological type $(n=1038)$ & & $<0.05$ \\
\hline Ductal $(n=763)$ & $94(12.3)$ & \\
\hline In situ $(n=93)$ & $2(2.2)$ & \\
\hline Lobular $(n=98)$ & $14(14.3)$ & \\
\hline Othter $(n=84)$ & $7(8.3)$ & \\
\hline Focality $(n=891)$ & & 0.461 \\
\hline Unifocal $(n=741)$ & $56(7.6)$ & \\
\hline Multifocal and/or multicentric $(n=150)$ & $14(9.3)$ & \\
\hline Histological grade $(n=905)$ & & 0.101 \\
\hline I $(n=228)$ & $19(8.3)$ & \\
\hline$\|(n=348)$ & $46(13.2)$ & \\
\hline III $(n=270)$ & $25(9.3)$ & \\
\hline Not applicable $(n=59)$ & $3(5.1)$ & \\
\hline Tumor phenotype $(n=763)$ & & 0.291 \\
\hline Luminal A $(n=404)$ & $41(10.1)$ & \\
\hline Luminal B $(n=207)$ & $12(5.8)$ & \\
\hline HER2 $(n=67)$ & $5(7.5)$ & \\
\hline Triple negative $(n=85)$ & $9(10.6)$ & \\
\hline
\end{tabular}

apercentages were computed as follows: number of women with persistent pain divided by the total number of women for each category
Table 3 Prevalence of persistent pain, according to the treatments performed

\begin{tabular}{|c|c|c|}
\hline & \multicolumn{2}{|c|}{ Persistent pain ${ }^{a}$} \\
\hline & N (\%) & $P$-value \\
\hline \multicolumn{3}{|l|}{ Surgery $(n=1043)$} \\
\hline Radical $(n=224)$ & $27(12.1)$ & 0.693 \\
\hline Conservative $(n=819)$ & $91(11.1)$ & \\
\hline Axillary treatment ${ }^{\mathrm{b}}(n=983)$ & & $<0.01$ \\
\hline Only SLNB $(n=268)$ & $18(6.7)$ & \\
\hline $\operatorname{ALND}(n=715)$ & $98(13.7)$ & \\
\hline Neoadjuvant therapy $(n=1045)$ & & 0.090 \\
\hline No $(n=936)$ & $111(11.9)$ & \\
\hline Yes $(n=109)$ & $7(6.4)$ & \\
\hline Adjuvant therapy post-surgery $(n=1039)$ & & 1 \\
\hline No $(n=26)$ & $3(11.5)$ & \\
\hline Yes $(n=1013)$ & $115(11.4)$ & \\
\hline Chemotherapy $(n=1018)$ & & $<0.01$ \\
\hline No $(n=513)$ & $43(8.4)$ & \\
\hline Yes $(n=505)$ & $73(14.5)$ & \\
\hline Radiotherapy ( $n=998)$ & & 0.457 \\
\hline No $(n=155)$ & $15(9.7)$ & \\
\hline Yes $(n=843)$ & $99(11.7)$ & \\
\hline Hormone therapy $(n=1019)$ & & 0.328 \\
\hline No $(n=219)$ & $29(13.2)$ & \\
\hline Yes $(n=800)$ & $87(10.9)$ & \\
\hline Her2 treatment $(n=1028)$ & & 0.790 \\
\hline No $(n=979)$ & $112(11.4)$ & \\
\hline Yes $(n=49)$ & $5(10.2)$ & \\
\hline
\end{tabular}

apercentages are computed as follows: number of women with persistent pain divided by the total number of women for each category

${ }^{b}$ SLNB: sentinel lymph node biopsy. In this category only women with SLNB performed were included. ALND: axillary lymph node dissection. This category includes women with only ALND performed and women with SLNB and ALND

had pain (either in the arm, breast area or shoulder) 3 months after surgery, but this information had to have been registered by the physician during the clinical course. If women had been asked the question "Do you have any pain?" the prevalence could possibly have been higher than $11.3 \%$. Our results might be interpreted as follows: $11.3 \%$ of women treated for breast cancer had clinically relevant pain, since pain was recorded in the medical record. In addition, some cultural differences may exist in pain perception. In a European survey of chronic pain, Spanish participants reported the lowest prevalence of chronic pain (12\%) [26]. Another possible reason for the low prevalence of persistent pain is that our patients came from screening and, therefore, had less aggressive tumors and less use of ALND than women with breast cancer of all ages, including those with a symptomatic diagnosis. 
Table 4 Factors associated with persistent pain: univariate and multivariate logistic regression models

\begin{tabular}{|c|c|c|c|c|c|c|c|c|}
\hline & \multicolumn{4}{|c|}{$\underline{\text { Univariate }}$} & \multicolumn{4}{|c|}{ Multivariate $^{a}$} \\
\hline & \multirow[b]{2}{*}{ OR } & \multicolumn{2}{|c|}{$95 \% \mathrm{Cl}$} & \multirow[t]{2}{*}{$P$-value } & \multirow[b]{2}{*}{ OR } & \multicolumn{2}{|c|}{$95 \% \mathrm{Cl}$} & \multirow[t]{2}{*}{$P$-value } \\
\hline & & Lower & Upper & & & Lower & Upper & \\
\hline \multicolumn{9}{|c|}{ Detection method $(n=1045)$} \\
\hline Screening & Ref. & & & & Ref. & & & \\
\hline Interval & 0.6 & 0.4 & 0.9 & 0.017 & 0.8 & 0.4 & 1.4 & 0.408 \\
\hline \multicolumn{9}{|l|}{ Age $(n=1045)$} \\
\hline $50-54$ & Ref. & & & & Ref. & & & \\
\hline $55-59$ & 1.1 & 0.7 & 1.9 & 0.618 & 1.0 & 0.5 & 2.0 & 0.967 \\
\hline $60-64$ & 0.9 & 0.5 & 1.5 & 0.632 & 0.7 & 0.3 & 1.6 & 0.424 \\
\hline $65-70$ & 0.7 & 0.4 & 1.3 & 0.282 & 0.7 & 0.3 & 1.7 & 0.432 \\
\hline \multicolumn{9}{|c|}{ Charlson index $(n=1045)$} \\
\hline 0 & Ref. & & & & Ref. & & & \\
\hline 1 & 2.3 & 1.5 & 3.7 & $<0.001$ & 2.8 & 1.4 & 5.4 & $<0.01$ \\
\hline$>=2$ & 3.0 & 1.8 & 5.2 & $<0.001$ & 4.5 & 2.1 & 9.5 & $<0.001$ \\
\hline \multicolumn{9}{|c|}{ Histological type $(n=1038)$} \\
\hline In situ & Ref. & & & & Ref. & & & \\
\hline Ductal & 6.4 & 1.5 & 26.4 & $<0.05$ & 0.5 & 0.1 & 4.2 & 0.534 \\
\hline Lobular & 7.6 & 1.7 & 34.4 & $<0.01$ & 1.1 & 0.5 & 2.7 & 0.784 \\
\hline Other & 4.1 & 0.8 & 20.5 & 0.082 & 0.6 & 0.2 & 2.1 & 0.422 \\
\hline \multicolumn{9}{|c|}{ Phenotype $(n=763)$} \\
\hline Luminal A & Ref. & & & & Ref. & & & \\
\hline Luminal B & 0.5 & 0.3 & 1.1 & 0.074 & 0.6 & 0.3 & 1.3 & 0.219 \\
\hline Her2 & 0.7 & 0.3 & 1.9 & 0.495 & 0.8 & 0.3 & 2.3 & 0.713 \\
\hline Triple negative & 1.0 & 0.5 & 2.2 & 0.903 & 1.1 & 0.5 & 2.6 & 0.800 \\
\hline \multicolumn{9}{|c|}{ Axillary treatment ${ }^{\mathrm{b}}(n=983)$} \\
\hline Only SLNB & Ref. & & & & Ref. & & & \\
\hline ALND & 2.2 & 1.3 & 3.7 & $<0.05$ & 2.0 & 1.0 & 4.0 & $<0.05$ \\
\hline \multicolumn{9}{|c|}{ Neoadjuvant treatment $(n=1045)$} \\
\hline No & Ref. & & & & Ref. & & & \\
\hline Yes & 0.5 & 0.2 & 1.1 & 0.095 & 0.4 & 0.1 & 1.3 & 0.132 \\
\hline \multicolumn{9}{|c|}{ Chemotherapy after surgery $(n=1018)$} \\
\hline No & Ref. & & & & Ref. & & & \\
\hline Yes & 1.8 & 1.2 & 2.8 & $<0.01$ & 1.4 & 0.7 & 2.5 & 0.334 \\
\hline
\end{tabular}

Among the risk factors described in the literature, young age is usually reported to be a risk factor for developing persistent pain $[5-7,10,12,14,17]$. In our study population, women aged $65-70$ years had the lowest prevalence of persistent pain, but the differences were not statistically significant. Since our study population only comprised women participating in populationbased breast cancer screening programs, we were unable to investigate persistent pain among women of younger ages (50 years or younger) or older ages (more than 70 years).

The presence of other comorbidities has been proposed as an associated factor in the development of persistent pain $[5,16]$. In our study, we investigated the presence of other comorbidities by using the Charlson index. Women with a Charlson index equal to 2 or higher had a much higher risk of developing persistent pain. It is well established that previous painful conditions predispose patients 
to persistent pain after surgery $[5,7,16]$. In addition, women with several comorbidities may have more depression, anxiety and other psychosocial factors that may also be risk factors for persistent pain [5, 27].

The use of ALND has been described in the literature as a risk factor for developing persistent pain $[6,7,10,12,14]$ and in our study remained a risk factor at the limit of statistical significance in the multivariate analysis. These studies report that women with an ALND had OR values between 2.0 and up to 7.7 and, in our study, women with an ALND had an OR of 2.0. This variability may be partly due to differences in the reference population: some studies take women without ALND as the reference, whereas others take those with SLNB as the reference category.

Some studies have found that chemotherapy is related to persistent pain $[5,11]$. In our study, the univariate analysis showed that women who received chemotherapy after surgery had a higher risk of persistent pain than those who did not but this result was not statistically significant in the multivariate analysis. Therefore, chemotherapy may be associated with the onset of persistent pain, but other factors are more strongly associated with to pain.

Our study has some limitations. Pain was not evaluated with validated instruments such the Visual Analogue Scale, Numerical Rating Scale or specific pain questionnaires, and could be underestimated. Most published evidence is based on pain measurement with validated instruments and therefore our results are not directly comparable to those of studies using these instruments. However, the value of reporting pain recorded in the medical record is a valid measure for clinically relevant pain, which could be comparable to the prevalence of moderate/severe pain reported in other studies. Moreover, our study did not collect women's height and weight, the two variables used to calculate the body mass index, a variable that has been proposed as a risk factor for developing persistent pain [14, 16]. Equally, variables related to psychosocial factors were not collected, which are well-established risk factors for persistent pain $[5,7,9,14]$. Finally, another limitation of our study is the lack of information on previous chronic pain conditions (such as low back pain, osteoarthritis, arthritis or fibromyalgia) $[5,16]$ or breast pain immediately before surgery $[11,14,16]$; all of these factors have been found to be related to the onset of persistent pain. Equally, no information was gathered on the presence of acute postoperative pain, another factor that it has been proposed as a risk factor for persistent pain [7]. However, the absence of these variables might not change our results on the effect of the detection method on the development of persistent pain.

This study has some important strengths. It is the first to evaluate the onset of complications and, specifically, persistent pain among women diagnosed with breast cancer participating in population-based screening programs in Spain. Our cohort study has a long follow-up period, with a median of 8.7 (Interquartile Range: 7.2 -10.6) years.

\section{Conclusions}

Our study shows that the detection mode (screening or interval) has no direct effect on the prevalence of complications and specifically on the onset of persistent pain. Although women with screen-detected cancer had a higher prevalence of persistent pain, the multivariate analysis showed that other factors were also associated with its onset, namely, Charlson index $>=2$ and the performance of an ALND.

In conclusion, the prevalence of persistent pain in our population of screened women was relatively low, and women with screen-detected cancers did not benefit from less persistent pain than women with interval cancer.

\section{Abbreviations}

ALND: Axillary lymph node dissection; Cl: Confidence intervals; ER: Estrogen receptor; HER2: Human epidermal growth factor receptor 2; OR: Odds ratio; PR: Progesterone receptor; SLNB: Sentinel lymph node biopsy

\section{Acknowledgments}

The authors acknowledge the dedication and support of the entire CAMISS Study Group (alphabetical order):

IMIM (Hospital del Mar Medical Research Institute), Barcelona: Xavier Castells, Imma Collet, Mercè Comas, Laia Domingo, Javier Louro, Francesc Macià,

Marta Roman, Anabel Romero, Maria Sala, Isabel Torà.

Canary Islands Health Service: Teresa Barata, Isabel Diez de la Lastra, Mariola de la Vega.

Corporacio Sanitaria Parc Tauli, Sabadell: Marisa Bare, Núria Torà. Hospital Santa Caterina, Girona: Joana Ferrer, Francesc Castanyer, Gemma Renart Epidemiology Unit and Girona Cancer Registry: Carmen Carmona. Hospital Galdakao-Usansolo, Vizcaya: Susana García, Maximina Martín, Miren Orive, Maria Amparo Valverde

Canary Islands Foundation for Health Research: Jeanette Pérez, Amado Rivero, Cristina Valcárcel

Hospital Costa del Sol, University of Málaga: María del Carmen Padilla, Maximino Redondo, Teresa Téllez, Irene Zarcos

Hospital Universitario Donostia /Biodonostia: Cristina Churruca, Amaia Perales, Javier Recio, Irune Ruiz, Cristina Sarasqueta, Jose María Urraca Instituto Oncológico de Guipúzcoa-Onkologikoa: Majesús Michelena Hospital Universitario Basurto: Julio Moreno

Hospital Universitario Cruces: Gaizka Mallabiabarrena, Patricia Cobos, Borja Otero

Hospital Universitario Txagorritxu: Javier Gorostiaga, Itsaso Troya Universitat de Lleida-IRBLLeida: Montserrat Rué, Montserrat Martínez-Alonso, Jorge Soler, Anna Pons

Universitat Rovira i Virgili: Misericòrdia Carles, Maria José Pérez, Roger Pla

\section{Funding}

This study was supported by grants from Instituto de Salud Carlos III FEDER (grant numbers: PS09/01153, Pl12/00387, PI11/01296 and PI15/00098) and by the Research Network on Health Services in Chronic Diseases (REDISSEC: RD12/0001/0015).

\section{Availability of data and materials}

Our dataset are not publicly available given that all data are confidential. In any case, if a research group is interested in analyzing our data, the investigators may get in contact with the corresponding author. improvement. AR has written the manuscript, and LD and MS have been 
involved in revising it critically for important intellectual content. $M B, T B$, JF, NT, CM and FM have been involved in acquisition of data and have collaborated in drafting the manuscript. All authors have given final approval of the version to be published.

\section{Competing interests}

The authors declare that they have no conflict of interest.

\section{Consent for publication}

Not applicable.

\section{Ethics and consent to participate}

Ethics: All procedures performed in this study were in accordance with the ethical standards of the institutional research committee and with the 1964 Helsinki declaration and its later amendments or comparable ethical standards. This study was approved by the ethics committee of Parc de Salut Mar (CEIC-Parc de Salut MAR), Barcelona.

Informed consent: Study data was collected under a protocol approved by the ethics committee of Parc de Salut Mar (CEIC-Parc de Salut MAR), Barcelona. In accord with this protocol, specific patient consent was not required since we used retrospective data from participants in the population-based breast cancer screening programs that signed information release documents previously.

\section{Author details}

'Department of Epidemiology and Evaluation, IMIM-Hospital del Mar, Research Network on Health Services in Chronic Diseases (REDISSEC), Passeig Marítim 25-29, Barcelona 08003, Spain. ${ }^{2}$ Clinical Epidemiology and Cancer Screening, Corporació Sanitària Parc Taulí-UAB, Research Network on Health Services in Chronic Diseases (REDISSEC), Sabadell, Spain. ${ }^{3}$ General Directorate of Health Care Programmes, Canary Islands Health Service, Las Palmas de Gran Canaria, Spain. ${ }^{4}$ Department of Radiology, Hospital de Santa Caterina, Salt, Girona, Spain. ${ }^{5}$ Agency for Health Quality and Assessment of Catalonia (AQuAS), Research Network on Health Services in Chronic Diseases (REDISSEC), Barcelona, Spain

Received: 11 March 2016 Accepted: 6 September 2016

Published online: 15 September 2016

\section{References}

1. Fact Sheets by Population [Internet]. [cited 2016 Jul 1]. Available from: http://globocan.iarc.fr/Pages/fact_sheets_population.aspx

2. Irvin VL, Kaplan RM. Screening mammography \& breast cancer mortality: meta-analysis of quasi-experimental studies. PLoS One. 2014;9(6):e98105.

3. Domingo L, Salas D, Zubizarreta R, Baré M, Sarriugarte G, Barata T, et al. Tumor phenotype and breast density in distinct categories of interval cancer: results of population-based mammography screening in Spain. Breast Cancer Res BCR. 2014;16(1):R3.

4. Andersen $\mathrm{KG}$, Kehlet $\mathrm{H}$. Persistent pain after breast cancer treatment: a critical review of risk factors and strategies for prevention. J Pain Off J Am Pain Soc. 2011;12(7):725-46.

5. Schou Bredal I, Smeby NA, Ottesen S, Warncke T, Schlichting E. Chronic pain in breast cancer survivors: comparison of psychosocial, surgical, and medical characteristics between survivors with and without pain. J Pain Symptom Manage. 2014;48(5):852-62

6. De Oliveira GS, Chang R, Khan SA, Hansen NM, Khan JH, McCarthy RJ, et al. Factors associated with the development of chronic pain after surgery for breast cancer: a prospective cohort from a tertiary center in the United States. Breast J. 2014:20(1):9-14

7. Bruce J, Thornton AJ, Powell R, Johnston M, Wells M, Heys SD, et al. Psychological, surgical, and sociodemographic predictors of pain outcomes after breast cancer surgery: a population-based cohort study. Pain. 2014;155(2):232-43.

8. Bell RJ, Robinson PJ, Nazeem F, Panjari M, Fradkin P, Schwarz M, et al. Persistent breast pain 5 years after treatment of invasive breast cancer is largely unexplained by factors associated with treatment. J Cancer Surviv Res Pract. 2014;8(1):1-8.

9. Belfer I, Schreiber KL, Shaffer JR, Shnol H, Blaney K, Morando A, et al. Persistent postmastectomy pain in breast cancer survivors: analysis of clinical, demographic, and psychosocial factors. J Pain Off J Am Pain Soc. 2013;14(10):1185-95.
10. Mejdahl MK, Andersen KG, Gärtner R, Kroman N, Kehlet H. Persistent pain and sensory disturbances after treatment for breast cancer: six year nationwide follow-up study. BMJ. 2013;346:f1865.

11. Sheridan D, Foo I, O'Shea H, Gillanders D, Williams L, Fallon M, et al. Longterm follow-up of pain and emotional characteristics of women after surgery for breast cancer. J Pain Symptom Manage. 2012;44(4):608-14

12. Alves Nogueira Fabro E, Bergmann A, do Amaral E, Silva B, Padula Ribeiro AC, de Souza Abrahão K, da Costa Leite Ferreira MG, et al. Post-mastectomy pain syndrome: incidence and risks. Breast Edinb Scotl. 2012;21(3):321-5.

13. Ewertz $M$, Jensen $A B$. Late effects of breast cancer treatment and potentials for rehabilitation. Acta Oncol Stockh Swed. 2011:50(2):187-93.

14. Miaskowski C, Cooper B, Paul SM, West C, Langford D, Levine JD, et al. Identification of patient subgroups and risk factors for persistent breast pain following breast cancer surgery. J Pain Off J Am Pain Soc. 2012;13(12):1172-87.

15. Li YYO, Kong SK. Persistent pain after breast cancer surgery in a Chinese population. Clin J Pain. 2011;27(6):481-5.

16. Sipilä R, Estlander A-M, Tasmuth T, Kataja M, Kalso E. Development of a screening instrument for risk factors of persistent pain after breast cancer surgery. Br J Cancer. 2012;107(9):1459-66.

17. Gärtner R, Jensen M-B, Nielsen J, Ewertz M, Kroman N, Kehlet H. Prevalence of and factors associated with persistent pain following breast cancer surgery. JAMA. 2009:302(18):1985-92.

18. Redondo M, Funez R, Medina-Cano F, Rodrigo I, Acebal M, Tellez T, et al Detection methods predict differences in biology and survival in breast cancer patients. BMC Cancer. 2012;12:604.

19. Mook S, Veer $\sqcup$ V't Rutgers EJ, Ravdin PM, van de Velde AO, van Leeuwen $\mathrm{FE}$, et al. Independent prognostic value of screen detection in invasive breast cancer. J Natl Cancer Inst. 2011;103(7):585-97.

20. Ascunce N, Salas D, Zubizarreta R, Almazán R, Ibáñez J, Ederra M, et al. Cancer screening in Spain. Ann Oncol Off J Eur Soc Med Oncol ESMO. 2010;21 Suppl 3:iii43-51.

21. Perry N, Broeders M, de Wolf C, Törnberg S, Holland R, von Karsa L. European guidelines for quality assurance in breast cancer screening and diagnosis. Fourth edition-summary document. Ann Oncol Off J Eur Soc Med Oncol ESMO. 2008;19(4):614-22.

22. Charlson ME, Pompei $P$, Ales KL, Mackenzie CR. A new method of classifying prognostic comorbidity in longitudinal studies: development and validation. J Chronic Dis. 1987:40(5):373-83.

23. Goldhirsch A, Wood WC, Coates AS, Gelber RD, Thürlimann B, Senn H-J, et al. Strategies for subtypes-dealing with the diversity of breast cancer: highlights of the St. Gallen International Expert Consensus on the Primary Therapy of Early Breast Cancer 2011. Ann Oncol Off J Eur Soc Med Oncol ESMO. 2011;22(8):1736-47.

24. Lyman GH, Giuliano AE, Somerfield MR, Benson AB, Bodurka DC, Burstein HJ, et al. American Society of Clinical Oncology guideline recommendations for sentinel lymph node biopsy in early-stage breast cancer. J Clin Oncol Off J Am Soc Clin Oncol. 2005;23(30):7703-20.

25. Classification of Chronic Pain, Second Edition (Revised) - IASP [Internet]. [cited 2016 Jun 22]. Available from: http://www.iasp-pain.org/PublicationsNews/ Content.aspx?ltemNumber $=1673$

26. Breivik H, Collett B, Ventafridda V, Cohen R, Gallacher D. Survey of chronic pain in Europe: prevalence, impact on daily life, and treatment. Eur J Pain Lond Engl. 2006;10(4):287-333.

27. Hickey OT, Nugent NF, Burke SM, Hafeez P, Mudrakouski AL, Shorten GD. Persistent pain after mastectomy with reconstruction. J Clin Anesth. 2011;23(6):482-8.

\section{Submit your next manuscript to BioMed Central and we will help you at every step:}

- We accept pre-submission inquiries

- Our selector tool helps you to find the most relevant journal

- We provide round the clock customer support

- Convenient online submission

- Thorough peer review

- Inclusion in PubMed and all major indexing services

- Maximum visibility for your research

Submit your manuscript at www.biomedcentral.com/submit
Biomed Central 